\title{
Rapid Intraoperative Tissue Expansion with Latex Glove after Large Nevus Excision for a Pediatric Patient: A Case Report
}

\author{
Sung Hoon Koh, Woong Gyu Na, Sung Won Jung, Hyoseob Lim \\ Department of Plastic and Reconstructive Surgery, Hallym University Sacred Heart Hospital, Hallym University Medical Center, Anyang, Korea
}

\begin{abstract}
Conventional concept of tissue expansion includes expander insertion, expander removal with wound coverage and intermittent expander inflations. Tissue expansion has been used in the various reconstruction area but high complication rates had been reported in the pediatric population. It may attribute to the inexperience of the medical team, poor education, improper follow-up and low compliance. Rapid intra-operative tissue expansion is a modified concept which utilizes the immediate expandability of the skin. Expansion forces are applied solely in the operative field and for only a short period of time. Ample volume of expansion has been reported in literature. We present the case of a 31-monthold female child with a giant nevus on the left upper arm. The nevus was excised and closed using a simple fabricated tissue expander. Expansion forces were applied only 25 minutes ( 15 minutes and 10 minutes with 5 minutes of intermittent break time) and the tissue was extended enough for tension free closure. The wound healed well without the complications like hematoma, seroma, wound dehiscence or necrosis.
\end{abstract}

Keywords: Tissue expansion, Intraoperative period, Reconstructive surgical procedures

\section{Introduction}

Tissue expanders have long been used in plastic and reconstructive surgery and are based on the skin's ability to stretch in response to mechanical forces [1,2]. Tissue expansion is also important as an effective reconstructive modality in the pediatric population. Conventional methods used for the expansion of the tissues followed a process of gradual inflation, with storage of the expanders in the soft tissues, and the entire process required extensive amounts of time. Unfortunately, high complication rates have been reported in infants and children $[3,4]$. Rapid intra-operative tissue expansion (RITE) is a modification of the original concept of tissue expansion that utilizes the immediate expandability of the skin [2]. Expansion forces are applied solely in the operative field and for only a short period of time. In the medical literature, sufficient tissue expansions by using RITE have been reported [2]. Here, we present the case of a 31-month-old female child with a giant nevus on the left upper arm. The nevus was excised and closed successfully with intra-operative tissue expansion by using a ballooning force that was applied solely in the operative field.

\section{Case}

A 32-month-old female child was referred to our department for the excision of a large nevus on her left upper arm. The nevus was congenital in origin and measured

\section{Case Report}

Received: November 23, 2017

Revised: January 4, 2018

Accepted: January 11, 2018

\section{Corresponding author:}

Sung Hoon Koh, M.D., Ph.D.

Department of Plastic and Reconstructive Surgery, Hallym University Sacred Heart Hospital, Hallym University Medical Center, 22 Gwanpyeong-ro 170beon-gil, Dongan-gu, Anyang 14068, Korea

Tel: $+82-31-380-3781$

Fax: +82-31-380-5980

E-mail: pshkoh@hallym.or.kr

This is an Open Access article distributed under the terms of the Creative Commons Attribution Non-Commercial License (http://creativecommons.org/licenses/by-nc/4.0/) which permits unrestricted non-commercial use, distribution, and reproduction in any medium, provided the original work is properly cited.

C 2018 Korean Wound Management Society 
Koh SH et al.

Rapid intraoperative tissue expansion
JWMR

by 10 minutes) until the peripheral skin blanching had almost disappeared with 5 minutes of intermittent rest period (Fig. 2). We palpated inflated expander with tension on the subcutaneous pocket margin area located beyond the nevus. After the expansion, an approximation of the peripheral flaps was performed, and the defect was expected to close without tension (Fig. 3). The nevus was excised and we identified intact dermal bleeding at the skin margin. The defect was then closed using 5-0 Nylon and 4-0 Polydioxanone sutures, and

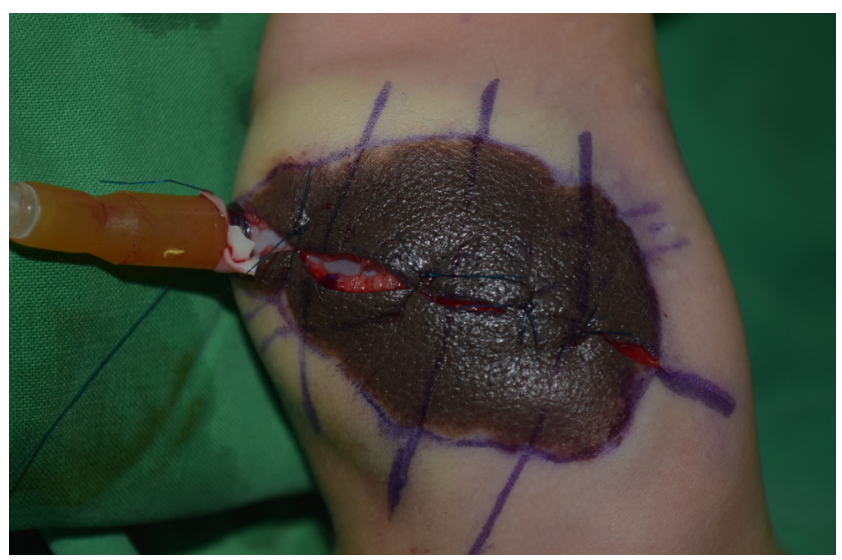

Fig. 2. Photography showing expander inflation.

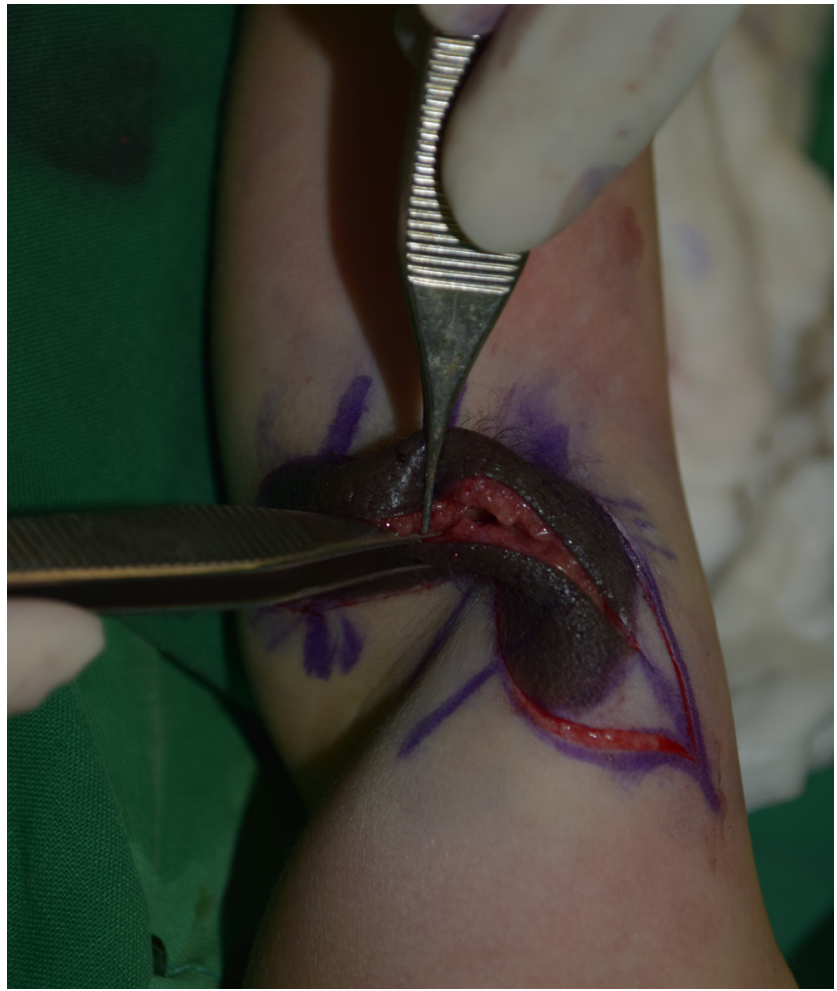

Fig. 3. Photography showing tension free closure.

Fig. 1. Preoperative gross photograph. 
Koh SH et al.

Rapid intraoperative tissue expansion

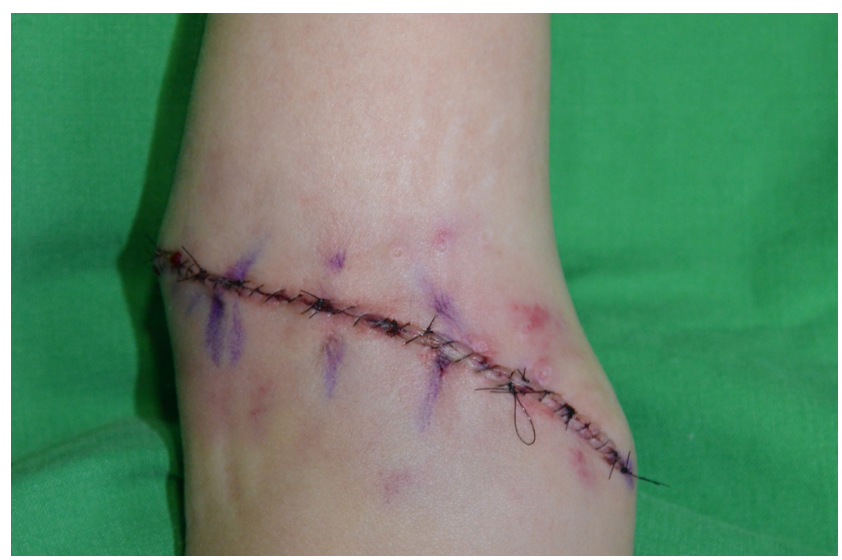

Fig. 4. Immediate postoperative photograph.

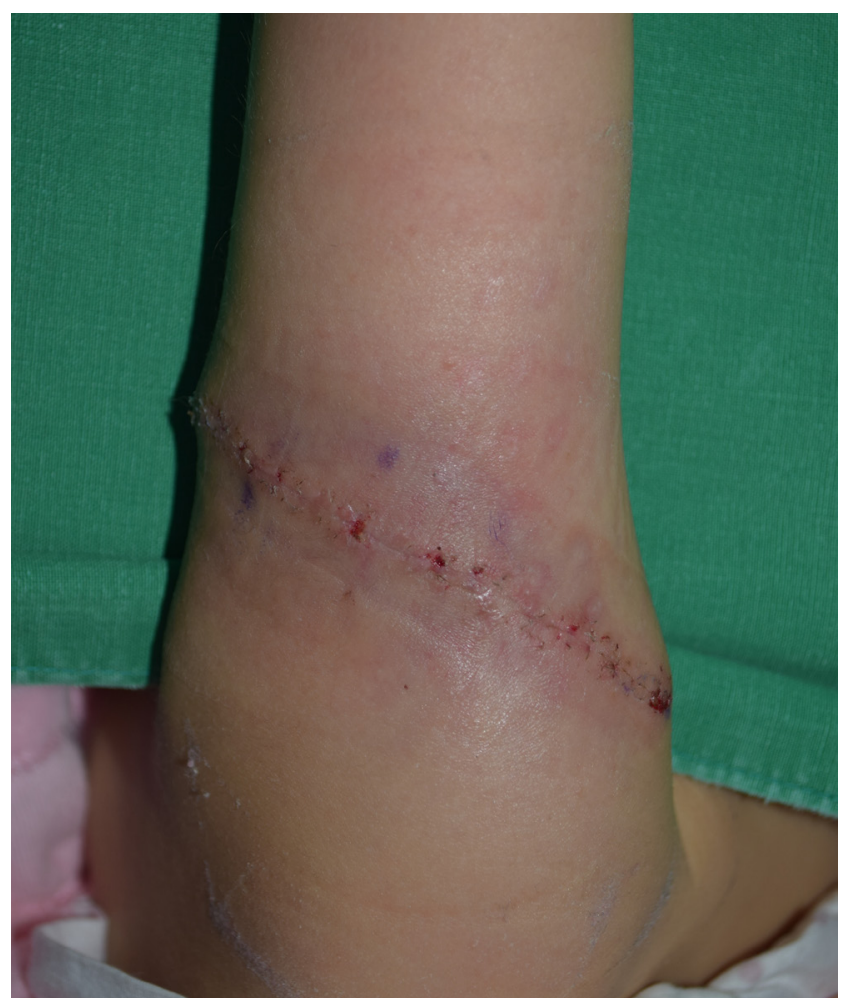

Fig. 5. Postoperative 14 days photograph.

the wound was dressed using a compression elastic bandage (Fig. 4).

The suture site was dressed using a foam material 4 days postoperatively in our outpatient department, and the sutures were removed on postoperative day 14 (Fig. 5). The pathologic examination confirmed congenital melanocytic nevus. Complications like hematoma, seroma, dehiscence or necrosis was not observed. Postoperative 30 months photograph show well-healed wound without significant complications (Fig. 6).
JWMR

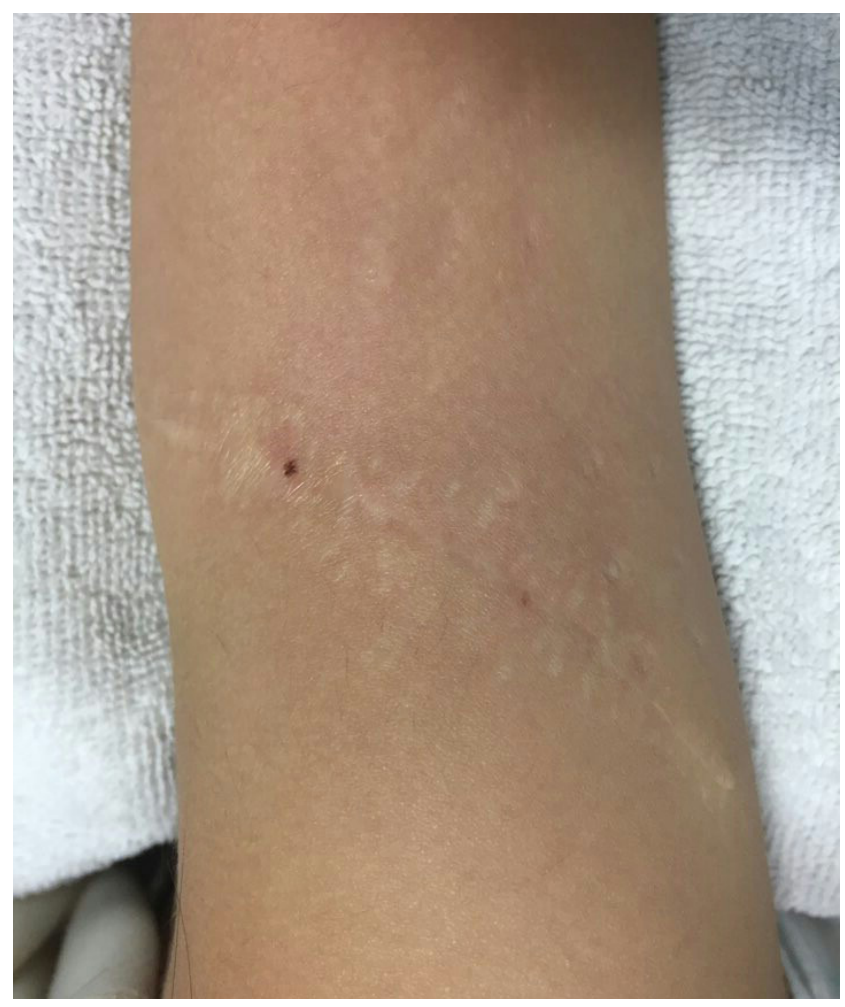

Fig. 6. Postoperative 30 months photograph.

\section{Discussion}

Since it was first reported in 1957, tissue expansion has been used in the reconstruction of various skin and soft tissue defects [4]. The original procedure for tissue expansion required a two-stage operation (expander insertion and expander removal with wound coverage), and intermittent expander inflations occurring over several weeks [5]. The physiologic changes associated with skin expansion include adjacent skin migration, cell proliferation, and angiogenesis [6]. Microscopic studies have reported an increase in the epidermal mitotic activity, dermal fibroblast numbers, and thickened elastic fibers in the expanded skin [2]. Many authors have yielded satisfactory functional and esthetic outcomes with gradual tissue expansion $[3,4,6]$. However, in the pediatric population, complication rates as high as $40 \%$ have been reported with tissue expansion [4]. The complications reported include infection, expander exposure or rupture, wound separation, and skin flap necrosis [1]. Although associations between age and complication rates have been debated, many authors have described higher complication rates in children $[3,4]$. This may be attributed to the inexperience of the medi- 
cal team, poor education, and improper follow-up [3]. A lack of compliance with medical care is another factor that is assumed to be associated with high complication rates [7]. In the literature, patients under the age of 12 years were reported to be less compliant and more likely to damage the expander [7]. Additionally, tissue expansion occurring in one of the childhood development periods could lead to a bony malformation [8]. It is possible that the external mechanical forces associated with tissue expansion could stimulate bone resorption and bone thinning [8]. Clinical studies have reported the existence of bony erosions and thinning under the forces of the expanders, with bone apposition at the periphery of the expander site in pediatric patients [8]. Fudem and Orgel documented the case of full thickness bony erosion that was found after tissue expansion in a 5-year-old patient [9].

RITE is a modified strategy for tissue expansion that occurs via mechanical creep [10]. Short periods of expansion forces rearrange the collagen fibers into a parallel pattern and also induce elastic fiber micro-fragmentation [2]. The ground substance is also displaced from the collagen network [2]. RITE has been performed for variable amounts of skin ranging from $15 \%$ to $31 \%$, as reported in the literature, and the success of the procedure seems to depend on the location and state of the host tissue and the degree of expansion $[2,11]$. In our case, two cyclic omnidirectional forces successfully expanded the overlying soft tissue, and the defect was closed without tension. The tissue inflation only required 25 minutes, and it was much more efficient compared to the classical tissue expansion procedure and the staged excision procedure, both of which inevitably would require secondary operations. The outpatient follow-up required after RITE inflation can be on a much less frequent basis compared to the follow-up required after a gradual expansion procedure [11].

Many authors used foley catheter or silicone expander for intraopeartive tissue expansion which is soft but harder than latex $[1,10,11]$. Soft material results in multidirectional expansion while rigid type expands unidirectionally [7]. Foley catheter or silicone could transfer expansion force on the central area but may be improper to expand marginal area of the pocket where the expander was inserted. They could not stretch to the marginal area and could not deliver expansion force on the peripheral area of the pocket directly. For our case, expansion of normal skin rather than nevus tissue is more critical for coverage which is located on the pocket peripheral area. Latex glove with sufficient elasticity could bal-
Ioon until it reaches the margin of the pocket and expand the tissue effectively.

In conclusion, RITE could be an effective reconstruction option for pediatric patients. Even though it is expected to be more limited with respect to the overall expansion achieved when compared to the gradual expansion process, complications including expander exposure, rupture, bone remodeling could be avoided. Also, the risks associated with an additional surgery and need for regular outpatient follow-up for gradual expansion could be evaded. Additionally, consideration about the ideal expander type could be benefit for surgeons. Even though latex material has less strength than other rigid expanders which may be vulnerable to rupture, it is suitable for RITE in pocket margin.

\section{Conflict of interest}

No potential conflict of interest relevant to this article was reported.

\section{References}

1. Hurvitz KA, Rosen H, Meara JG. Pediatric cervicofacial tissue expansion. Int J Pediatr Otorhinolaryngol 2005 69(11): 1509-13.

2. Johnson TM, Lowe L, Brown MD, et al. Histology and physiology of tissue expansion. J Dermatol Surg Oncol 1993; 19(12):1074-8.

3. LoGiudice J, Gosain AK. Pediatric tissue expansion: indications and complications. J Craniofac Surg 2003;14(6):86672.

4. Margulis A, Billig A, Elia J, et al. Complications of post-burn tissue expansion reconstruction: 9 years experience with 42 pediatric and 26 adult patients. Isr Med Assoc J 2017; 19(2):100-4.

5. Wagh MS, Dixit V. Tissue expansion: Concepts, techniques and unfavourable results. Indian J Plast Surg 2013;46(2): 333-48.

6. Han Y, Zhao J, Tao R, et al. Repair of craniomaxillofacial traumatic soft tissue defects with tissue expansion in the early stage. J Craniofac Surg 2017;28(6):1477-80.

7. Braun TL, Hamilton KL, Monson LA. Tissue expansion in children. Semin Plast Surg 2016;30(4):155-61.

8. El-Saadi MM, Nasr MA. The effect of tissue expansion on skull bones in the paediatric age group from 2 to 7 years. J Plast Reconstr Aesthet Surg 2008;61(4):413-8. 
Koh SH et al.

Rapid intraoperative tissue expansion

9. Fudem GM, Orgel MG. Full-thickness erosion of the skull secondary to tissue expansion for scalp reconstruction. Plast Reconstr Surg 1988;82(2):368-9.

10. Doshier LJ, Fowler D, McEwan T, et al. Intraoperative tissue expansion in the surgical correction of craniosynostosis.
Plast Surg (Oakv) 2015;23(1):21-4.

11. Cakmak M, Gollu G, Kucuk G, et al. Rapid intraoperative tissue expansion with Foley catheter in a challenging cripple Hypospadias. Int Braz J Urol 2015;41(3):591-5. 